\title{
Preventing Weight Regain: What's the Importance of Body Image Change after Bariatric Surgery?
}

\section{Micanti F*, Loiarro G, Pecoraro G and Galletta D}

Department of Neuroscience, Reproductive Science and Odontostomatology, School of Medicine, "Federico II" Naples, Italy

${ }^{*}$ Corresponding author: Fausta Micanti, MD, Department of Neuroscience, USD: Psychiatry, UOS: Eating Disorder and Obesity, Via Pansini, 5 80122 Naples, Italy, Tel: +39 330875129; Fax: +39 0817462372; E-mail: micanti@unina.it

Received date: September 07, 2016; Accepted date: October 25, 2016; Published date: November 01, 2016

Copyright: @ 2016 Micanti F, et al. This is an open-access article distributed under the terms of the Creative Commons Attribution License, which permits unrestricted use, distribution, and reproduction in any medium, provided the original author and source are credited.

\begin{abstract}
Introduction: Obese patients have a high degree of body dissatisfaction and uneasiness inducing feelings of low self-esteem, sadness and loneliness leading to the development of pathological social withdrawal. Change of body image dimension is considered a factor for weight maintenance. The aim of this study is to show that, after bariatric surgery at weight loss, body image partially changes which could be considered one of the reasons for long term weight regain after bariatric surgery.
\end{abstract}

Method: 40 patients: mean age $38 \mathrm{SD} \pm 10,71 ; 28$ women, 12 men; mean body mass index (BMI) $48 \mathrm{SD} \pm 8,31$, suffering from severe obesity, were enrolled in this study. All participants were evaluated before and after bariatric surgery. The assessment at weight loss after bariatric surgery $\left(t_{1}\right)$ was performed using BUT test. The statistical data analysis was performed with the t-Student method $(p<0.05)$.

Results: Results after bariatric surgery were: sufficient ability to cope with the nutritional program for bariatric surgery; change in eating behavior; fulfilled perception of satiety and reduction in food intake impulse; improvement of body image in its cognitive and behavioral components, but not in the emotional one.

Conclusion: Weight loss is insufficient to determine a change in the emotional component of body image. It does not interfere with the emotional regulation system or with the ability to use non-verbal communication. Improving ability to perceive one's new body and the knowledge of how to use it in relationship with others is necessary to prevent risk of weight regain after bariatric surgery.

Keywords: Bariatric surgery; Body image; Weight regain

\section{Introduction}

Obesity is a multifactorial disease. Its etiopathogenesis results from genetic, metabolic and psychological factors. Its mental dimensions are: impulsiveness, body image, anxiety and mood. Body Image is a multidimensional structure formed of three components: perception, cognitive-affect, behaviour [1]. Body image and appearance has a relevant role in structuring the motivation for weight loss and maintenance. Body dissatisfaction and uneasiness is reinforced by social image. Currently the message coming from social networks stresses the equivalence between fat-loser person/slim-winner person. It can contribute to the development of the thought that being slim could realize every desire, eliminate every pathological trait in human relation and improve body dissatisfaction.

Obese subjects usually ask for bariatric surgery pushed by the dissatisfaction of their own body and the desire to have a new slim one accepted by society. They have a high degree of body dissatisfaction and uneasiness that play a role in inducing feelings of low self-esteem, sadness and loneliness that can lead to the development of pathological social withdrawal [2]. Obese subjects consider their body as an object to be accepted or rejected without any ability to perceive it as part of their identity [3]. The poor correlation between body dissatisfaction and body mass index (BMI) stresses the importance of perceptive and affective components in transforming the quality of body image [4]. In the same way, educational level does not seem to influence body image uneasiness. All studies about the constitution of body image in obese subjects emphasize that it is closely connected to the characteristics of the affective bond, making a difference between the onset obese and those who become obese in adolescence or adulthood. The onset obese subjects have a negative body image as a result of negative judgement of their fatness and of their inability to lose weight, expressed by parents or family [5]. The obese adults develop negative body image under different pressures: the inadequacy of their body related to the winner model and the inner factor concerning the thin-ideal internalization [6-9].

Body Image becomes a symbol of every problem due to the lack of a complete construction of self. The incomplete development of an integrated Self, from body experience to mind, is produced by pathological affective bond [10]. In time, obese subjects build a strategy to hide their body or to enhance feelings of indifference for social activity, particularly group activities. Furthermore, body uneasiness, as object of the relationship with others, changes into feelings of estrangement and lack of acknowledgement of fat entity. Often, patients realize the real fat entity when they need help to shower, to put their shoes on, to sit down. Controlled studies show that an interchangeable relation exists between eating behavior, regulation of hungry-satiety system and enhancement of body image particularly as the effect of weight loss $[11,12]$. 
Bariatric surgery inducing weight loss also through the regulation of hunger-satiety system determines an improvement of the emotional regulation system and of body image mental dimension. However, almost all studies consider an overall body image change and only few investigated the quality of it because there are not so many instruments able to detect the variations of the three components of body image. BUT is a test validated in Italian language and was employed because it has the specific aim of investigating not only body dissatisfaction, but also other dimensions of so-called negative body image. It measures body dissatisfaction and the elements of negative body image such as body shape, weight dissatisfaction, body image related to avoidance behaviors, compulsive body checking behaviors, detachment and feelings of estrangement towards one's own body and specific worries about particular body parts, shapes or functions. It is formed by two parts: BUT A and BUT B. BUT A includes five subscales defined as follows: Weight Phobia (fear of being or becoming fat): WP; Body Image Concerns (over-concern with physical appearance): BIC; Avoidance (avoidance behaviors related to body image): A; Compulsive Self-monitoring (compulsive checking of physical appearance): CSM; Depersonalization (detachment and feelings of estrangement towards the body): D determining the Global Severity Index (GSI). BUT-B has 37 items arranged in eight subscales that look at specific worries about particular body parts or functions determining the Positive Symptom Index (PSI). Among them we consider particularly the BUT B III subscale (stomach, abdomen, hips, thighs, knees) because it investigates those parts of body that are more frequently objects of dissatisfaction and uneasiness above all for obese women. BUT can help to evaluate the effect on body image of obesity treatment: bariatric surgery and medical management $[13,14]$. These tests were administered in a self-report way. Studies about weight regain underline that the incomplete acceptance of body image can contribute to weight regain after two/three years from bariatric surgery $[9,15]$.

The aim of this study is to show that weight loss is insufficient to determine a change of the three body image components. Specifically it does not change the emotional component related to the internal and external cues and the ability to use non-verbal communication. This unaccomplished change can be considered one of the causes of weight regain.

\section{Materials and Method}

40 patients: mean age $38 \mathrm{SD} \pm 10,71 ; 28$ women, 12 men; mean body mass index (BMI) $48 \mathrm{SD} \pm 8,31$ (Table 1 ), suffering from severe obesity, were enrolled in this study. They were assessed for bariatric surgery: sleeve or gastric by-pass. Every patient underwent the multi disciplinary assessment for bariatric surgery: surgical, medical, nutritional and psychological screening. They had had five years of various and unsuccessful diets along with drugs such as amphetamine. All had clinical comorbidities: hypertension, type II diabetes, metabolic syndrome. Patients were referred to the Eating Disorder and Obesity Unit of the School of Medicine "Federico II" Naples by the regional Bariatric surgery Units for the psychological/psychiatric assessment. All participants signed a written voluntary informed consent form before entering the study.

\section{The psychological assessment before bariatric surgery $\left(t_{0}\right)$ consisted of}

Psychiatric examination to exclude psychiatric disorders according to the Diagnostic and Statistical Manual of Mental Disorders-5 [16].
Exclusion criteria for bariatric surgery were: schizophrenia spectrum and other psychotic disorders, bipolar and related disorders, depressive disorders, anxiety disorders, obsessive-compulsive and related disorders, dissociative disorders, feeding and eating disorders such as bulimia, binge eating disorder (BED) and night eating syndrome (NES) as Bariatric surgery guidelines (ASMBS) and Inter disciplinary European Guidelines on Metabolic and Bariatric Surgery recommended $[17,18]$.

\begin{tabular}{|l|c|c|}
\hline \multicolumn{1}{|c|}{ Gender } & $\mathbf{1 2} \mathbf{~ M}$ & $\mathbf{2 8 ~ F}$ \\
\hline Mean age & \multicolumn{2}{|c|}{$38 \pm 10,71$} \\
\hline Mean BMI & $\mathrm{t}_{0}: 48 \pm 8,31$ & $\mathrm{t}_{1}: 33 \pm 8,58$ \\
\hline \multirow{3}{*}{ Eating Behavior } & Gorging & 11 \\
\cline { 2 - 3 } & Snacking & 12 \\
\cline { 2 - 3 } & Grazing & 11 \\
\cline { 2 - 3 } & Binge Episodes & 6 \\
\hline
\end{tabular}

Table 1: Gender, mean age, mean BMI, eating behaviors of the sample.

Structured Interview to identify the type of eating behavior: gorging, snacking, grazing and binge. Binge was excluded if it is a symptom of mood disorders, personality disorder, impulse control disorder, BED and bulimia. It was included if it was a symptom of binge eating disorder of low frequency and/or limited duration (DSM-5).

Psychodiagnostic screening was performed using Binge Eating Scale (BES) to assess binge eating and Body Uneasiness Test (BUT) to evaluate Body Image [19,20] (Figure 1).

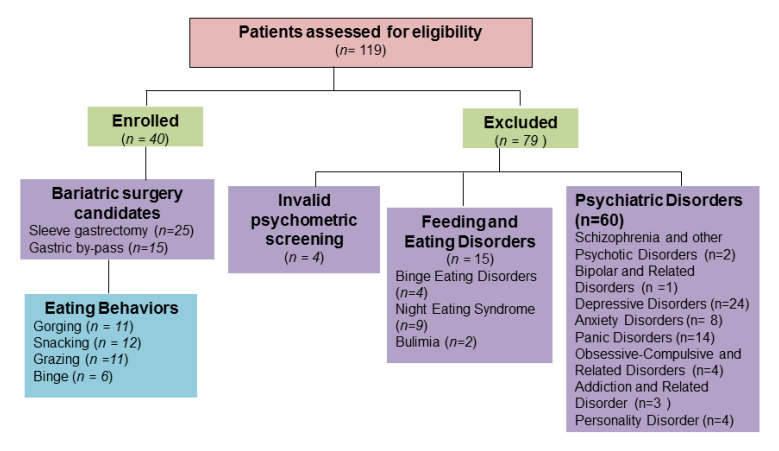

Figure 1: Recruitment flow chart.

\section{The psychological assessment after bariatric surgery at weight loss $\left(t_{1}\right)$ consisted of}

Clinical examination to evaluate compliance to the nutritional program and the possible presence of eating disorders.

BUT test to compare the results with those of $\mathrm{t}_{0}$

Statistical data analysis was performed with the t-Student method $(\mathrm{p}<0.05)$. 
Page 3 of 4

\section{Results}

At baseline ( $\left.\mathrm{t}_{0}\right)$, the following results were found: 1) Clinical assessment showed: 40 patients with metabolic syndrome; $10 / 40$ had hypertension, $5 / 40$ had type II diabetes. $\mathrm{M}_{\mathrm{BMI}}$ was $48 \mathrm{SD} \pm 8.31$. At Psychiatric examination, patients showed: eating behavior: 11/40 gorging; $12 / 40$ snacking; $11 / 40$ grazing; $6 / 40$ binge episode as symptom of Binge Eating Disorder of Low Frequency and/or limited duration. Sufficient motivation in reaching weight loss coping with bariatric procedure. Psychometric analysis showed: food intake impulsiveness of medium entity: MBES scores 14,65; BUT: BUT A and B subscales showed high scores of WP, BIC, A, D, CSM and GSI, PSI and BUT III subscale (stomach, abdomen, hips, thighs, knees) (Table 2). GSI score, PSI, BUT III scores indicated high levels of body dissatisfaction and uneasiness.

\begin{tabular}{|c|c|c|c|}
\hline BUT subscales & $\mathbf{t}_{0}{ }^{\mathrm{a}}$ & $\mathbf{t}_{1}{ }^{\mathrm{b}}$ & $p<0,05$ \\
\hline \multirow{2}{*}{ Weight Phobia (WP) } & M 2,31 & M 1,46 & \multirow{2}{*}{0,017} \\
\hline & SD 1,5 & SD 1,17 & \\
\hline \multirow{2}{*}{ Body Image Concerns (BIC) } & M 2,47 & M 1,18 & \multirow{2}{*}{0,0004} \\
\hline & SD 1,58 & SD 1,03 & \\
\hline \multirow{2}{*}{ Avoidance (A) } & M 1,69 & M 0,58 & \multirow{2}{*}{0,003} \\
\hline & SD 1,8 & SD 0,9 & \\
\hline \multirow{2}{*}{ Compulsive Self-Monitoring (CSM) } & M 1,19 & M 0,89 & \multirow{2}{*}{0,24} \\
\hline & SD 1,17 & SD 0,77 & \\
\hline \multirow{2}{*}{ Depersonalization (D) } & M 1,32 & M 0,47 & \multirow{2}{*}{0,007} \\
\hline & SD 1,48 & SD 0,76 & \\
\hline \multirow{2}{*}{ GSI } & M 1,83 & M 1 & \multirow{2}{*}{0,005} \\
\hline & SD 1,34 & SD 0,82 & \\
\hline \multirow{2}{*}{ PSI } & M 16,33 & M 11,24 & \multirow{2}{*}{0,05} \\
\hline & SD 10,27 & SD 9,43 & \\
\hline
\end{tabular}

Table 2: Body Uneasiness Test (BUT) subscale mean scores and standard deviations.

At follow-up time (t1) the results were: 1) At clinical assessment: weight loss with a sufficient reduction of $\mathrm{BMI}: \mathrm{M}_{\mathrm{BMI}}=33,6$ and $\mathrm{SD} \pm$ 8,58; absence of hypertension and type II diabetes; good clinical and nutritional conditions. Bariatric type of operation: 25/40 sleeve, 15/40 gastric by-pass; absence of surgical complications in the short and long term. 2) At psychiatric examination: absence of post-surgical eating avoidance disorder (PSEAD); sufficient ability to cope with the nutritional program for bariatric surgery; change in eating behavior as above: gorging decrease of food intake quantity; snacking reduction of number and quality of snacks; grazing and binge increase of inhibitory control of food intake as mean BES score shows; fulfilled perception of satiety recognized by patients as a real support for diet maintenance; improvement of body image in its cognitive and behavioral components, but not of the emotional one. GSI BUT A and PSI had a reduction. BUT A subscales: WP, BIC, A, D showed a low significant improvement; CSM had a major increase. BUT B: B III showed a low decrease of dissatisfaction for these specific body parts (stomach, abdomen, hips, thighs, knees) (Table 2).

\section{Discussion}

The comprehensive analysis of the results showing no failure in post-operation period in coping with bariatric procedure such as Postsurgical Eating Disorder, underlines that a multidisciplinary careful screening before bariatric surgery is a necessary step for its effectiveness $[17,18]$. At weight loss, data analysis stresses that no difference between sleeve and gastric by-pass in both short and long term were found. They produce a sudden and good improvement of subjects' physical condition, particularly for diabetes and hypertension [21]. The improvement of physical condition, peculiar to the effect of bariatric surgery, contributes to the enhancement of quality of life reinforcing change of eating behavior [22]. Subjects report a new feeling of being in good shape, retrieving the ability of physical independence. This feeling acts as a strong push for the nutritional program because the motivation for seeking bariatric surgery is based, in most cases, on dissatisfaction and uneasiness of body, or on the onset of clinical pathology that reduces the subject's quality of life. All these conditions contribute to increasing the weight loss process and the consequent body image change [23]. Data analysis suggests that a specific improvement of body image really exists, after weight loss $\left(t_{1}\right)$ induced by sleeve or gastric by-pass. BUT data show the reduction of GSI and PSI testifying a general improvement of the body dissatisfaction and uneasiness. The analysis of the single subscale highlights that WP, BIC, does not significantly improve emphasizing that the emotional component of body image barely changes. The decrease of A and D subscales is much more connected to reduction of GSI and PSI because both can determine the arousal of avoidance and feelings of estrangement as a consequence of the negative body image. Therefore, weight loss induces change of the cognitive and behavioral components connected to the improvement of physical ability such as to walk quickly, to bend down, to sit on every type of chair as emphasized by CSM factor statistical significant variation [24]. These new feelings contribute tothe maintenance of the nutritional program. The low significance of subscale B III mean score related to WP and BIC indicates, especially for women, the endurance of dissatisfaction for specific parts of their body stressing the insufficient change in the emotional quality of body image. The overall analysis highlights that weight loss and maintenance have a high risk of failure determining weight regain and new revisional surgery. Weight loss is not sufficient to determine a change of body image emotional component related to the internal and external cues. Specifically, weight loss does not interfere with the emotional regulation system or with the ability to use non-verbal communication. The lack of the ability to perceive a new body and the knowledge of how to use it inrelationship with others represent a high risk for weight regain $[15,25,26]$.

\section{Conclusion}

Weight regain can be determined by the lack of integration of the three components of body image. The endurance of the emotional component disorder does not allow patients to take possession of their new body. The feeling and memory of being fat can determine the invariance of one's relationship with society and reduce the inhibitory control of food intake causing weight regain. It seems clear that it is necessary to perform, after losing weight, other types of support to facilitate the integration of body image and weight maintenance and prevent risk of weight regain after bariatric surgery. 


\section{Limit}

One limit of this study is that it does not present the results of different therapeutic cues for achieving the integration of body Image. These data could highlight that it is necessary to establish psychotherapy in the follow-up program to obtain weight maintenance and a real change in mental health.

\section{References}

1. Cash T, Smolak L (2011) Body image: a handbook of science, practice and prevention. The Guilford Press inc., New York

2. Annis NM, Cash TF, Hrabosky JI (2004) Body image and psychosocial differences among stable average weight, currently overweight and formerly overweight women: the role of stigmatizing experience. Body Image 1: 155-167.

3. Price HI, Gregory DM, Twells LK (2014) Body shape expectations and self-ideal body shape discrepancy in women seeking bariatric surgery: a cross-sectional study. BMC Obesity 1: 28.

4. Sarwer DB, Thompson JK, Cash TF (2005) Body image and obesity in adulthood. Psychiatr Clin North Am 28: 69-87.

5. Weng SF, Redsell SA, Swift JA, Yang M, Glazebrook CP (2012) Systematic review and meta-analyses of risk factors for childhood overweight identifiable during infancy. Arch Dis Child 97: 1019-1026.

6. Ata RN, Thompson JK, Small BJ (2013) Effects of exposure to thin-ideal media images on body dissatisfaction: testing the inclusion of a disclaimer versus warning label. Body Image 10: 472-480.

7. Asberg KK, Wagaman A (2010) Emotion Regulation Abilities and Perceived Stress as Predictors of Negative Body Image and Problematic Eating Behaviors in Emerging Adults. AJPR 6: 193-217.

8. Voelker DK, Reel JJ, Greenleaf C (2015) Weight status and body image perceptions in adolescents: current perspectives. Adolesc Health Med Ther 6: 149-158.

9. Lerner HM, Klapes B, Mummert A, Cha E (2016) Body size perception and ideal body size in overweight and obese young adult women. Eat Weight Disord 21: 487-492.

10. Lichtenberg JD (1989) Psychoanalysis and motivation. The Analytic Press Inc. Hillsdale, New Jersey.

11. Carraça EV, Silva MN, Teixeira PJ (2013) Body image investment and self-regulation of weight control behaviors. In Leroy B. Sams and Janet A. Keels (Eds). Handbook on Body Image: Gender Differences, Sociocultural Influences and Health Implications. Nova Publishers.

12. Ginis MKA, McEwan D, Josse AR, Phillips SM (2012) Body image change in obese and overweight women enrolled in a weight-loss intervention: The importance of perceived versus actual physical changes. Body Image 9: 311-317.

13. Cuzzolaro M, Vetrone G, Marano G, Garfinkel PE (2006) The Body Uneasiness Test (BUT): development and validation of a new body image assessment scale. below Eat Weight Disord 11: 1-13.
14. Marano G, Cuzzolaro M, Vetrone G, Garfinkel PE, Temperilli F, et al. (2007) Validating the Body Uneasiness Test (BUT) in obese patients. Eat Weight Disord 12: 70-82.

15. Sawamoto R, Nozaki T, Furukawa T, Tanahashi T, Morita C, et al. (2016) Predictors of Dropout by Female Obese Patients Treated with a Group Cognitive Behavioral Therapy to Promote Weight Loss. Obes Facts 9: 29-38.

16. American Psychiatric Association (2013) Diagnostic and statistical manual of mental disorder, DSM-5. American Psychiatric Publishing, Inc.

17. American Association of Clinical Endocrinologists, The Obesity Society, and American Society for Metabolic and Bariatric Surgery (2013) Clinical practice guidelines for the perioperative nutritional, metabolic, and nonsurgical support of the bariatric surgery patient - 2013 update. Surg Obes Relat Dis 9: 159-191.

18. Fried M, Yumuk V, Oppert JM, Scopinaro N, Torres AJ, et al. International Federation for the Surgery of Obesity and Metabolic Disorders-European Chapter (IFSO-EC) and European Association for the Study of Obesity (EASO) (2014) Interdisciplinary European Guidelines on Metabolic and Bariatric Surgery. Obes Surg 24: 42-55.

19. Gormally J, Black S, Daston S, Rardin D (1982) The assessment of binge eating severity among obese persons. Addict Behav 7: 47-55.

20. Grupski AE, Hood MM, Hall BJ, Azarbad L, Fitzpatrick SL, et al. (2013) Examining the Binge Eating Scale in screening for binge eating disorder in bariatric surgery candidates. Obes Surg 23: 1-6.

21. Bruno G, Gruden G, Barutta F, Perin CP, Morino M, et al. (2015) What is the impact of sleeve gastrectomy and gastric bypass on metabolic control of diabetes? A clinic-based cohort of Mediterranean diabetic patients. Surg Obes Relat Dis 11: 1014-1019.

22. Ardestani A, Rhoads D, Tavakkoli A (2015) Insulin Cessation and Diabetes Remission After Bariatric Surgery in Adults With InsulinTreated Type 2 Diabetes. Diabetes Care 38: 659-664.

23. Carraça EV, Silva MN, Markland D, Vieira PN, Minderico CS, et al. (2011) Body image change and improved eating self-regulation in a weight management intervention in women. Int J Behav Nutr Phys Act 8: 75.

24. Teufel M, Rieber N, Meile T, Giel KE, Sauer H, et al. (2012) Body image after sleeve gastrectomy: reduced dissatisfaction and increased dynamics. Obes Surg 22: 1232-1237.

25. Micanti F, Loiarro G, Cucciniello C, Pecoraro G, Galletta D (2016) Can Body Group Therapy after Bariatric Surgery be Effective to Avoid Weight Regain? A Clinical Experience. J Obes Weight Loss Ther 6: 3

26. Niazi M, Maleki AR, Talebpour M (2013) Short-term outcomes of laparoscopic gastric plication in morbidly obese patients: importance of postoperative follow-up. Obes Surg 23: 87-92. 